\title{
OS INVISÍVEIS DA EDUCAÇÃO INFANTIL: OS DESAFIOS EM TEMPO DA PANDEMIA
}

\author{
Alana Gabriele da Silva ${ }^{1}$ \\ Maria Adriana de Souza Silva Santos ${ }^{2}$ \\ Maria de Lourdes Oliveira ${ }^{3}$
}

RESUMO: Este artigo teórico visa relatar, de uma forma significativa, a importância de visibilizar as crianças da Educação Infantil em época de pandemia causada pelo novo coronavírus, dado que elas foram as mais afetadas na área educacional com a necessidade do isolamento social, pois precisam de auxílio para desenvolver as atividades propostas. Embora essa etapa da Educação Básica seja considerada uma das mais importante, pois desenvolve o indivíduo como um ser íntegro, os alunos desta têm sido postergados e se tornam invisíveis. Portanto, a partir de investigações em estudos prévios, o objetivo deste artigo é enfatizar a importância dos cuidados, nos quais visibilizam o sistema educacional de aprendizagem para que nesta fase ocorra um aprendizado integral das crianças da Educação Infantil.

Palavras-chave: Educação infantil. Desafios. Pandemia.

ABSTRACT: This theoretical article aims to report, in a significant way, the importance of making children in Kindergarten visible at a time of pandemic caused by the new coronavirus, given that they were the most affected in the educational area with the need for social isolation, as they need help to develop the proposed activities. Although this stage of Basic Education is considered one of the most important, as it develops the individual as a being of integrity, its students have been postponed and become invisible. Therefore, based on investigations in previous studies, the aim of this article is to emphasize the importance of care, in which the educational learning system is made visible so that, at this stage, a comprehensive learning process for children in Kindergarten takes place.

Keywords: Childhood education. Challenges. Pandemic.

\footnotetext{
IEspecialista em Docência do Ensino Superior pelo instituto de ensino FAVENI, Graduada em Letras/ Inglês e Pedagogia pela Universidade do Sagrado Coração, Bauru e Professora da Educação Básica na rede pública do estado de São Paulo. E-mail:alanagdasilva@gmail.com.

${ }_{2}^{2}$ Especialista em Pedagogia, gestão e planejamento educacional Faculdade Escritor Osman Lins. FACOL. Graduada em Pedagogia, Pesquisadora integrante do grupo de pesquisa GEPERGES Audre Lorde UFRPE, professora do Ensino Fundamental anos iniciais do ensino Público de Pernambuco. E-mail: adriana200531@gmail.com.

${ }^{3}$ Mestranda em Educação Global, Desenvolvimento Humano e Gestão da Inovação (Flórida Christian University- FCU),Graduada em Pedagogia professora da Educação Infantil da rede pública do estado São Paulo. E-mail: maluoliveirapedagoga@gmail.com.
} 


\section{INTRODUÇÃO}

Crianças invisibilizadas, quem são e o que aconteceu com elas? $O$ que seria essa invisibilidade em tempos de isolamento social causado pelo coronavírus? Muitas são as perguntas para esse e outros acontecimentos, que ocorreram com a propagação da Covid-ı pelo mundo.

Houve mudanças extremas com a implementação das medidas sanitárias restritivas a fim de obter um cuidado para não colapsar o sistema mundial de saúde. De acordo com a Organização Mundial da Saúde (OMS) 2020, as medidas obrigatórias são necessárias para a contenção e propagação do vírus, salvando um maior número de vidas.

Diante disso, o fechamento das instituições de ensino foi uma das maneiras encontradas para não ocorrer a aglomeração, conseqüentemente, alunos, professores, gestores e outros indivíduos que trabalham para o sistema de ensino foram obrigados a ficar em casa para que diminuísse o número de contaminação.

Neste sentido, a escola teve que exercer sua função social buscando coletivamente fazer suas adaptações mediante a sua realidade. Portanto, ocorreu grande dedicação por parte de toda equipe escolar, objetivando a continuação do processo de ensino aprendizagem no "novo normal".

Assim, as aulas remotas ganharam espaço na vida cotidiana dos brasileiros, para que o ensino e aprendizagem continuassem sendo desenvolvidos. Porém, diversos fatores internos e externos tiveram que ser respaldados.

Para manter as aulas virtuais e conseguir prosseguir com a rotina de estudos, os alunos precisam de aparelhos eletrônicos para efetivar essa estratégia. Além disso, com a inserção desses dispositivos as crianças menores, ou seja, crianças da Educação Infantil foram as que mais encontraram dificuldades para serem inseridas, dado que ainda não têm o domínio tecnológico necessário.

Em conseguinte, esse comportamento afeta diretamente as crianças da Educação Infantil, pois são abandonadas, causando então, certa invisibilidade para elas. Bem como, o direito ao ensino é excluído, ignorando a garantia por lei. 
Portanto, este artigo objetiva compreender quem são essas crianças pequenas, como elas estão sendo afetadas e como professores e comunidades devem agir mediante essa problemática.

$\mathrm{O}$ artigo está subdividido em três tópicos, sendo o primeiro capítulo o papel da escola, e sua transformação com a chegada da pandemia. O segundo, uma reflexão sobre o professor e sua atual posição no novo normal. Seguido do terceiro tópico, no qual retrata as crianças da educação infantil, e como são invisibilizadas devido ao ensino remoto. Por fim, as considerações finais e as respectivas referências.

\section{A CONTRIBUIÇÃO DA ESCOLA E SUAS LEGALIDADES EM ÉPOCA DE ISOLAMENTO SOCIAL}

A pandemia da covid-I9, tornou-se um marco na vida de todos que presenciaram sua causalidade, por ser uma doença contagiosa e letal tornou-se tão devastadora, que muitos foram os acontecimentos que simultaneamente surgiram em todo o mundo.

A escola como instituição social de desenvolvimento humano e de acolhimento de pessoas passou a ser apenas um prédio com seus portões fechados, paredes isoladas, evitando o contato físico com seu público-alvo, e esse espaço de interação social forçosamente se isolou.

Para que essa instituição fosse mesmo que provisoriamente fechada várias medidas tiveram que ser tomadas como leis, decretos e resoluções, a escola não tinha condições de cumprir com suas obrigações e exercer seu papel institucional para com a sociedade. (ARAÚJO,2020).

Esse espaço escolar tem uma contribuição significativa na vida de seus alunos, e mesmo com suas limitações, está cumprindo com seus direitos e deveres, exercendo suas funções mesmo que remotamente, e assim contribuir para solucionar o problema. Diante disso, Pereira e Castelo Branco (200I)

A escola, sendo um espaço de aprendizagens e afetividades, nuclear na aquisição de saberes e competências, é simultaneamente um espaço de ambigüidades, de contradições e expectativas, onde os diversos contextos sociais exigem respostas e esperam soluções para os problemas que assolam a complexa sociedade em que vivemos (CASTELO-BRANCO; PEREIRA, 200I, p. 336). 
De acordo com a citação acima a escola como instituição responsável pelas contribuições educacionais a partir da perspectiva de acolhimento e interação, mesmo com toda sua limitação estrutural, vem sendo uma das protagonistas desse momento de atenção mundial.

A medida que o tempo pandêmico foi prolongando o Ministério da Educação (MEC), por meio da portaria no 343 (BRASIL, 2020), resolveu e publicou uma normativa a qual especifica como será ministrada as aulas.

A portaria dispôs sobre a substituição das aulas presenciais por aulas em meios digitais enquanto durasse a situação de pandemia do novo coronavírus, inicialmente por um período de trinta dias, prorrogáveis, a depender da orientação do Ministério da Saúde e dos órgãos de saúde estaduais, municipais e distritais.

À medida que a pandemia tomava rumos com números de casos de contaminação devastadores surgiam novas normas e resoluções, a fim de tentar solucionar as questões educacionais. Diante disso a escola como instituição de ensino físico e presencial, adotou a educação por meio remoto

Deste modo em especial, evitaria a necessidade de reposição ou prorrogação do atendimento ao fim do período de emergência, acompanhando tão somente o mesmo fluxo das aulas da rede de ensino como um todo, quando do seu retorno. (BRASIL, 2020, p. 9).

Essa citação refere-se à necessidade de um planejamento para se ajustar o calendário escolar e os dias letivos. Visto isso, para garantir o direito a Educação a

escola passou a adotar essa modalidade de ensino remoto, e abranger a maior quantidade de alunos possíveis para tentar solucionar a defasagem educacional frente ao isolamento social.

\section{I.I AS ATRIBUIÇÕES DA ESCOLA}

Os acontecimentos durante a pandemia fizeram com que a escola buscasse meios legais para orientar-se e entender quais os caminhos deveriam ser seguidos, um exemplo foi no dia 18 de março de 2020, quando uma Nota de Esclarecimento do Conselho Nacional de Educação (BRASIL, 2020), doravante CNE (Conselho Nacional de Educação) aponta sobre a possibilidade de realização de atividades a distância, atribuindo aos Sistemas de Ensino autorizar e organizar as mesmas. 
Com isso, medidas foram tomadas a fim de tentar oferecer as aulas na modalidade remota, desde então, intensificam as discussões quanto à viabilidade desta proposta de trabalho para a Educação Básica, em especial para a Educação Infantil, por suas especificidades e, mais particularmente, pela idade das crianças atendidas.

De acordo com a LDB, encontramos em seu artigo 32, § $4^{\circ}$, a previsão de ensino a distância para o Ensino Fundamental como complementação de aprendizagem ou em situações emergenciais. No artigo 36 , § II, há a possibilidade da educação a distância para o Ensino Médio. No entanto, no que se refere à Educação Infantil, não foram encontradas as referências na Lei.

Mesmo não encontrando essa modalidade de ensino a distância para o Ensino Fundamental anos iniciais, e especialmente para Educação Infantil, deste modo com toda a causalidade da pandemia da Covid-ı9 a Educação Infantil também foi contemplada com o ensino remoto.

No dia 28 de abril de 2020, o CNE aprova o Parecer 05/2020, que trata da reorganização do calendário escolar e da possibilidade de cômputo de atividades não presenciais para fins de cumprimento de carga horária mínima anual, em razão do quadro pandêmico. Em relação à Educação Infantil, assim se expressa:

\footnotetext{
No sentido de contribuir para minimização das eventuais perdas para as crianças, sugere-se que as escolas possam desenvolver alguns materiais de orientações aos pais ou responsáveis com atividades educativas de caráter eminentemente lúdico, recreativo, criativo e interativo, para realizarem com as crianças em casa, enquanto durar o período de emergência, garantindo, assim, atendimento essencial às crianças pequenas e evitando retrocessos cognitivos, corporais (ou físicos) e socioemocionais ( BRASIL, 2020, p.9)
}

Portanto, a expressão acima mostra a preocupação do desenvolvimento íntegro. Dessa maneira, a criação desse parecer, pode-se concluir que essa garantia de educação remotamente para crianças pequena, ou seja, as crianças da Educação Infantil precisam vivenciar algumas atividades de forma lúdica e recreativa.

$\mathrm{Na}$ Lei de Diretrizes e Bases da Educação Nacional, lei no 9.394, seção II, a Educação Infantil é considerada a etapa da Educação Básica que tem por finalidade o desenvolvimento integral da criança de até 5 (cinco) anos, em seus aspectos físicos, psicológicos, intelectual e social, complementando a ação da família e da comunidade (BRASIL 1996). 
De acordo com Shudo e Sallum (2016), ingressar na escola antes do Io ano tem um efeito positivo sobre o desempenho escolar, levando a resultados significativos (p. 8); para isto, a Base Nacional Comum Curricular (BNCC) define o conjunto orgânico e progressivo de aprendizagens essenciais que todos os alunos devem desenvolver ao longo das etapas e modalidades da Educação Básica, afirma que a Educação Infantil deve assegurar seis direitos de aprendizagem e desenvolvimento, são esses conforme Nova Escola (2020): Conviver; Ser; Brincar; Participar; Explorar e Expressar.

\section{OS DOCENTES E SUAS CONTRIBUIÇÕES}

Por muitos anos, os professores foram representados por pessoas bravas e irredutíveis, sendo quase ditadores do conhecimento em sala de aula. Esses personagens são resultado dos docentes da pedagogia tradicional, os quais eram os agentes principais de conhecimentos. Nesse cenário, os educadores eram os únicos que podiam se expressar, enquanto os alunos apenas recebiam os conteúdos e tinham que memorizá-los. Assim como em Libâneo (2006):

predomina a autoridade do professor que exige atitude receptiva dos alunos

e impede qualquer comunicação entre eles no decorrer da aula. $\mathrm{O}$ professor transmite o conteúdo como verdade a ser absorvida; em conseqüência, a disciplina imposta é o meio mais eficaz de assegurar a atenção e o silêncio (LIBÂNEO, 2006, p. 24).

Como citado acima, a sala de aula era um cenário silencioso, e não expressivo, dado que os alunos não podiam compartilhar seus conhecimentos. Bem como, as vivências prévias dos estudantes não eram interessantes para o desenvolvimento do processo de ensino e aprendizagem na época.

Porém, com o passar dos anos, estudiosos começaram a voltar sua atenção para o cenário educacional, e muitas teorias, metodologias, métodos e estratégias foram desenvolvidos.

Por meio de estudos, especialistas como Wallon, Piaget e outros alteraram a visão do ensinar e aprender. Em Oliveira (1992) Vygotsky pontua que o pensamento tem sua origem nas inclinações, necessidades, interesses, impulsos, afeto e emoção. Logo, tem sua gênese na esfera motivacional. 
O processo começou a levar em consideração as experiências prévias dos alunos, além de sua total interação e comunicação com os colegas do ambiente. Dessa maneira, o professor torna-se tutor. Sendo assim, ele não é mais apenas o detentor do conhecimento, mas é também um aprendiz dos alunos

O trabalho docente é atividade que dá unidade ao binômio ensinoaprendizagem, pelo processo de transmissão-assimilação ativa de conhecimentos, realizando a tarefa de mediação na relação cognitiva entre o aluno e as matérias de estudo. (LIBÂNEO, I994, p. 88)

Libâneo, então, enfatiza a importância dessa mudança, principalmente, porque os conteúdos não são mais transmitidos, mas são alterados conforme as experiências prévias dos alunos para que participem de maneira ativa na construção do seu conhecimento.

Além disso, o ensino atual visa o desenvolvimento integral do aluno, tornando-o protagonista do seu processo de ensino e aprendizagem. Essa construção favorece o ser humano como um todo, e o torna apto para ser um cidadão crítico e reflexivo em seu ambiente social.

Esse papel de organizador de conhecimento começa na Educação Infantil, sendo uma das mais importantes, visto que desenvolve o indivíduo de maneira íntegra. $\mathrm{Na}$ proposta de 2000, o professor da Educação Infantil precisa:

Organizar situações de aprendizagem adequadas à criança de quatro a seis anos a partir da compreensão de que vivem um processo de ampliação de experiências com relação à construção das linguagens e dos objetos de conhecimento, considerando o desenvolvimento, em seus aspectos afetivo, físico, psico-social, cognitivo e lingüístico (MEC/SEMTEC, 20oo, p. 73)

É observado, então, a importância do desenvolvimento linguístico, cognitivo e competências considerando o socioemocional. Bem como é expressa também na Lei de Diretrizes e Base (9394/96):

A Educação Infantil, primeira etapa da Educação Básica, tem como finalidade o desenvolvimento integral da criança até seis anos de idade, em seus aspectos físico, psicológico, intelectual e social, complementando a ação da família e da comunidade.” (LDB, CAP.II; SEÇÃ̃II; ART.29LDB)

Mais uma vez o desenvolvimento íntegro aparece quando se é tratado sobre Educação Infantil. Portanto, embora a pandemia tenha negligenciado essa fase de ensino, sua posição é relevante na Educação Básica. E para que esse desenvolvimento continue 
ocorrendo, os professores tiveram que se (re)adaptar de acordo com sua realidade frente ao isolamento social causado pelo novo coronavírus.

\section{I As atribuições docentes na pandemia}

Como mencionado anteriormente, com a chegada do novo coronavírus, houve a necessidade de isolamento social para que o sistema de saúde não entrasse em colapso e vidas fossem preservadas. Portanto, de maneira quase instantânea as escolas alteraram sua rotina, pois ocorreu o isolamento social. Principalmente a classe docente precisou ser transformada:

As professoras e os professores, sobretudo de educação básica, já encontravam dificuldades anteriores à pandemia, tanto pela carga horária extraclasse, quanto pela remuneração e condições de exercício no que toca às ferramentas de trabalho. A precarização da classe professoral não é uma temática nova (PALUDO, 2020, p. 45)

Nessa parte da história, mesmo com as adversidades mencionadas na citação anterior, os professores agora são mais que tutores e organizadores de conhecimentos, na verdade, eles se tornaram a peça fundamental para que o processo de ensino $e$ aprendizagem continuasse da melhor maneira possível.

Portanto a inserção de aparelhos tecnológicos foi necessária e útil, principalmente em tempo de pandemia. Alejandra Behar et al. (2019), ressalta que as tecnologias digitais servem para a sociedade continuar andando sincronicamente, e sua utilização deve ser feita já nos anos iniciais, objetivando a aprendizagem.

Porém, quando se trata da Educação Infantil, apenas a dificuldade em relação a utilização da tecnologia não é o problema principal, pois nessa etapa de ensino as crianças precisam de um apoio, já que estão desenvolvendo não apenas a parte cognitiva, mas a motricidade e várias outras competências socioemocionais.

Vygotsky (1998, apud FANTACHOLI, 2009), disserta que a brincadeira é relevante na infância e tem ligação direta com o ensino e aprendizagem na construção do sujeito, sendo uma maneira de expressão e construção em relação ao mundo e as relações sociais. Portanto, o lúdico ocorre por meio das vivências e experiências específicas. 
Dessa forma, os docentes precisam não apenas passar adiante o conteúdo, mas buscar estratégias para que as crianças pequenas tenham os materiais e apoios necessários, principalmente, o familiar, realizando reflexões críticas sobre os exercícios realizados para que realmente seja efetivado o desenvolvimento íntegro.

Bem como, o professor se tornou peça fundamental para atender as divergentes demandas da Educação Infantil, visto que nem todos os familiares conseguem acompanhar os estudos dos alunos, seja por falta de tempo, escolarização e/ou outros fatores como o não acesso às tecnologias.

Por fim, a Educação Infantil, foi uma das mais atingidas com a chegada do novo coronavírus, e as crianças ficaram invisíveis devido às dificuldades dos professores frente às diversas adversidades encontradas frente à tecnologia e aos exercícios lúdicos.

\section{AS CRIANÇAS E SUAS REPRESENTAÇÕES}

As crianças da Educação Infantil seguem sua trajetória de aprendizagens rumo à alfabetização, portanto estas se colocam no ambiente escolar como sujeitos de suas ações, embora em uma ação inconsciente elas organizam suas aprendizagens por meio das interações com os pares.

Desta forma, neste processo de aquisição do conhecimento contam com a contribuição dos mediadores entre a criança e o objeto do conhecimento, estes podem ser a família, os educadores e mesmo suas ações dentro da comunidade, onde está inserida. Portanto, suas representações estão diretamente interligadas, sendo umas de maior intensidade e outras de menor intensidade.

Um dos momentos de maior interação da criança dentro do ambiente escolar é o recreio, no qual propicia maior autonomia e liberdade de escolha para participar de grupos de maior afinidade. Dentro destes grupos, as crianças se afirmam por meio de suas representatividades, buscando construir sua identidade como sujeito de suas ações representadas por intermédio do brincar, conforme coloca Palma;

Engana quem concebe as culturas da infância como homogêneas, universais; uma mesma informação ou situação adquire significações diferentes para cada criança, como resultado das suas experiências de vida, dos cenários sociais e culturais onde estabelece relações com os adultos e 
com os pares, de acordo ainda com sua condição econômica, gênero, etnia ou localização geográfica. (PALMA, 2017, s/p).

Portanto se cada criança tem sua própria maneira de organizar o conhecimento de acordo com suas vivências, e nessas experiências em momento de pandemia se dão sem um acompanhamento da escola essa mediação entre a criança e o conhecimento pode ser prejudicada por falta de interações, tornando-as invisíveis, tanto no sentido de avaliação do desenvolvimento, quanto nas questões de acompanhamento das aprendizagens propostas.

\section{I As crianças da educação infantil na pandemia}

Em tempos de pandemia a educação se dá por meio de múltiplas ações a fim de se adequar à nova realidade. Para a Educação Infantil, estes desafios se apresentam ainda maiores por se tratar de crianças dependentes, somando todas as dificuldades, e o fato de que muitas pessoas ainda não têm claro a importância desta etapa. Tal falta de clareza permeia grande parte dos atores na formação da criança.

Crianças pequenas estão em uma fase em que se faz necessário o trabalho com o brincar e se apresenta a importância do letramento, dessa forma, se trata de uma fase subjetiva dando margens a muitas interpretações.

Ao desvalorizar esta etapa pode ocasionar dificuldades na alfabetização da criança em todos os campos, pois o déficit de hoje tende a repercutir nas estratégias de recuperação do amanhã, reconhecendo ser a etapa final da Educação Infantil o processo de transição para a aquisição do conhecimento e a alfabetização.

Portanto, a ênfase à Educação Infantil segundo Cruz, Martins e Cruz (202I) trata-se de uma obrigação legal a atenção prioritária às crianças. Logo, não é facultativo por qualquer indivíduo no período de pandemia.

Com o advento da crise da covid-ı muitas demandas se apresentaram na área da educação, entre tantas resoluções as mais frequentes preocupações na Educação Infantil estão relacionadas com a necessidade dos pais em ter um local adequado para deixar as crianças.

Assim, o questionamento do desenvolvimento fica para momento posterior. Deste modo, se formam o grupo dos invisíveis da Educação Infantil, os quais são os motivadores 
que contribuem com este fator, dentre eles pode-se destacar a falta de tecnologia, o alcance limitado das atividades por questões diversas.

Mesmo ao buscar resoluções governamentais para a situação de pandemia, em uma relação de respostas organizada por setores da educação como o Fundo Nacional de Educação (FNDE) é verificado a referência de uma preocupação às outras etapas. Sem mencionar a Educação Infantil quanto aos aspectos referentes a educação remota. Portanto, fica esta responsabilidade a cargo de professores, escolas e familiares.

\subsection{A interação da família no desenvolvimento das crianças na educação infantil}

A criança formula seu aprendizado com base em suas vivencias, é com a família que acontece o seu primeiro contato social, por meio desta que entende e interage com o mundo. Seu olhar está voltado ao ambiente em que está inserido. É por meio deste que cria e recria suas impressões sobre o mundo a sua volta, portanto as interações da criança com a família estão relacionadas com as suas ações dentro do ambiente escolar. Como afirma Saltini (1997)

Neste caso, o educador serve de continente para a criança. Poderíamos dizer, portanto, que o continente é o espaço onde podemos depositar nossas pequenas construções e onde elas tomam um sentido, um peso e um respeito, enfim, onde elas são acolhidas e valorizadas, tal qual um útero acolhe um embrião (SALTINI, 1997, p. 89).

No contexto de isolamento social, estas relações se tornam mais importantes, pois a criança pequena depende de um adulto para as suas realizações, porém este contato está reduzido e as interações ocorrem em menor quantidade. Assim, vivências de qualidade podem potencializar o aprendizado. Já a não ocorrência delas são elementos fortalecedores para o processo de invisibilidade das crianças. Neste sentido, trabalhar a afetividade de forma positiva se apresenta como uma possível estratégia de reduzir estes impactos, pois de acordo com WALLON (1995):

A afetividade é um domínio funcional, cujo desenvolvimento dependente da ação de dois fatores: o orgânico e o social. Entre esses dois fatores existe uma relação recíproca que impede qualquer tipo de determinação no desenvolvimento humano, tanto que a constituição biológica da criança ao nascer não será a lei única do seu futuro destino. Os seus efeitos podem ser amplamente transformados pelas circunstâncias sociais da sua existência onde a escolha individual não está ausente (WALLON, 1995, p. 288). 
De acordo a citação acima, a afetividade é determinada pela vivência, bem como potencializa as interações com os pares mesmo que de forma virtual tem sido um meio de aproximação dos alunos. Porém em muitos casos, se faz necessário uma busca por meios mais eficazes a fim de se estabelecer novas relações com alunos.

Muitos são os que não têm acesso às tecnologias, portanto ações modificadoras se fazem necessárias para que se tenha uma educação, na qual todos contemplem sua visibilidade a partir de elementos capazes de promover a inclusão. Em face disso é necessário considerar questões cognitivas e afetivas, visto que segundo Piaget (1976)

[...] vida afetiva e vida cognitiva são inseparáveis, embora distintas. E são inseparáveis porque todo intercâmbio com o meio pressupõe ao mesmo tempo estruturação e valorização. Assim é que não se poderia raciocinar, inclusive em matemática, sem vivenciar certos sentimentos, e que, por outro lado, não existem afeições sem um mínimo de compreensão. (PIAGET, 1976, p. 16).

Piaget lembra que a afetividade é de suma importância para o desenvolvimento cognitivo, então é necessário potencializar as interações entre a família e a escola. Esta estratégia é primordial para sanar os processos de invisibilidade da criança, tornando-a parte de um todo, no qual poderá realizar suas aprendizagens por meio de suas representações e interações com os pares.

\section{CONSIDERAÇÕES FINAIS}

A pandemia embora tenha trazido muitos prejuízos, também está carregada de avanços e reflexões importantes. Uma delas, é o esquecimento do Ensino Infantil, em tempo de isolamento social em razão da COVID-ı.

Após a discussão e análises das legislações é observado que a educação infantil, embora seja um direito universal e uma das etapas mais importante da educação, foi simplesmente apagada. Conseqüentemente, invisibilizando as crianças e negligenciando seu processo de ensino e aprendizagem.

Com a chegada da pandemia e a ocorrência do isolamento social, as aulas presenciais foram alteradas para o modelo de aulas remotas em um curto espaço de tempo. Portanto, essas (re)adaptações deixaram lacunas que até o momento não foram preenchidas em relação a algumas etapas da Educação Básica, principalmente, na Educação Infantil. 
Essa fase é a mais importante dentro da Educação Básica, porque por meio dela se desenvolve o indivíduo de maneira integral visando muito além do cognitivo. Ademais, nela é necessário experiências direcionadas para as aprendizagens, seja por meio do brincar ou de outras vivências.

Apesar dos familiares se esforçarem, bem como, criar estratégias para que a escolarização continue, a problemática está muito além do que eles podem fazer. Dado que, por meio dos aparelhos tecnológicos não é possível desenvolver as atividades lúdicas, seja porque as crianças ainda não têm o domínio deles ou porque elas não têm o apoio suficiente de familiares e/ou responsáveis.

Resultando, então, na modificação do papel do professor, quem não é apenas um tutor, mas um "tradutor" dos processos de ensino e aprendizagens para as famílias, a fim de que elas sejam capazes de realizar as atividades com as crianças enfatizando conteúdos e vivências a mais do que estão sendo propostas.

\section{REFERÊNCIAS}

BEHAR, Patricia Alejandra; SCHORN, Gabriella Thais; DA SILVA, Ketia Kellen Araújo. Mapeamento de Competências Digitais para o aluno dos Anos IniciaisCOMPDig_AI. RENOTE, v. 17, n. I, p. 507-516, 2019.

BRASIL. LDB. Lei de Diretrizes e Bases da Educação: Lei no 9.394/96. Disponível em: http://www.planalto.gov.br/ccivil_03/leis/19394.htm. Acesso em i6 jun.202I.

, MEC. Ministério da Educação FNDE, Conselho Deliberativo do FNDE

Disponivel em: https://www.gov.br/mec/pt-br/assuntos/noticias/conselho-deliberativodo-fnde-aprova-novas-resolucoes-para-garantia-do-desenvolvimento-do-ensino-nopais Acesso em:24/Jun/2021

- Ministério da Educação. Base Nacional Comum curricular, Educação é a Base. $2018 . \quad$ Disponível em: http://basenacionalcomum.mec.gov.br/images/BNCC_EI_EF_IIO5I8_versaofinal_site.pdf . Acesso em: 13 jun. 2021.

. Portaria $\mathrm{n}^{\circ} 343$, de 17 de março de 2020. Dispõe sobre a substituição das aulas presenciais por aulas em meios digitais enquanto durar a situação de pandemia do Novo Coronavírus - COVID-ı9. Brasília, DF: Ministério da Educação, 2020a. Disponível em: https://www.in.gov.br/en/web/dou/-/portaria-n-343-de-17-de-marco-de-2020-248564376 . Acesso em: I4 de jun. 202I. 
- Ministério da Educação. Conselho Nacional de Educação.Parecer CNE/CP no . 5/2020. Brasília/DF: Ministério da Educação, 28 abr. 2020. Disponível em http://portal.mec.gov.br/index.php?option=com_docman\&view=download \& alias=I450II\%20pcpoo5-20\&category_slug=marco-2020-pdf\&Itemid=30192. Acesso em: I4 jul. 202I.

. Conselho Nacional de Educação. Parecer CNE/CP no. II/202o. Brasília/DF: Ministério da Educação, 07 de julho de 2020. Disponível em: http://portal.mec.gov.br/docman/julho-2020-pdf/I4839i-pcpori-20/file . Acesso em: i4 jun. 2021.

CASTElO-BRANCO, M. C. A. S. Hall; PEREIRA, A. M. de S. P. A Auto-estima, a satisfação com a imagem corporal e o Bem-estar Docente. Psicologia, Educação e Cultura, vol no 2, p.335-346, 2001 .

CRUZ, Silvia Helena Vieira; MARTINS, Cristiane Amorim; DE ANDRADE CRUZ, Rosimeire Costa. A educação infantil e demandas postas pela pandemia: intersetorialidade, identidade e retorno às atividades presenciais. Zero-a-Seis, v. 23, bn. Especial, p. 147-174, 2021.

FANTACHOLI, F. DAS N. A Importância do Brincar na Educação Infantil - Brasil Escola. Disponível em: https://monografias.brasilescola.uol.com.br/educacao/aimportancia-brincar-na-educacaoinfantil.htm. Acesso em: 2I jun. 202I.

LIBÂNEO, José Carlos. Democratização da Escola Pública: a pedagogia críticosocial dos conteúdos. 2i ${ }^{\mathrm{a}}$ ed. São Paulo: Loyola, 2006.

Didática. I. ed. São Paulo: Cortez, 1994.

PALMA, Mìriam Stock.Rev.Port.de Educação. vol,30 no.2. Braga dez.2017

PALUDO, Elias Festa. Os desafios da docencia em tempos de pandemia. Em Tese, Florianópolis, v.17, n.2, p. $44-53$, jul/dez., 2020. Universidade Federal de Santa Catarina. Disponível em: https://periodicos.ufsc.br/index.php/emtese/article/view/ı8o65023.2020vi7n2p44/44232. Acesso em: 21 jun. 2021.

PIAGET, VYGOTSKY, WALLON. Teorias psicogenéticas em discussão. Yves de La Taille, Martha Kohl de Oliveira, Heloysa Dantas. I4º ed.- São Paulo: Summus, 1992.

PIAGET, J. A construção do real na criança. Rio de Janeiro: Zahar, 1976.

SALTINI, Cláudio J. P. Afetividade \& inteligência. Rio de Janeiro: DPA, 1997

WALLON, H. A evolução psicológica da criança. 2 ed. Lisboa: Edições 70, 1995. 